\title{
RESPONSIVIDADE REFLEXIVA: UM CONCEITO PARA MEIOS CRIATIVOS DE TRANSFORMAÇÃO EM PRÁTICAS COLABORATIVAS-DIALÓGICAS
}

\author{
RESPONSIVIDAD REFLEXIVO: UN CONCEPTO PARA MEDIOS CREATIVOS \\ DE TRANSFORMACIÓN EN PRÁCTICAS DIALÓGICAS-COLABORATIVAS
}

BRUNO LENZI

Instituto Movimento, Florianópolis/SC, Brasil
RESUMO: Este artigo descreve experiências no contexto da terapia colaborativa-dialógica, que tocaram minha curiosidade e criatividade. Sentimentos que me fizeram refletir sobre minha prática e buscar autores que me ajudassem a desenvolver uma descrição para o que veio a se tornar um conceito para 0 diálogo. Encontrei em autores das práticas dialógicas as articulações que precisava para amadurecer aquilo que vinha sentindo na prática. Responsividade Reflexiva é um conceito que investiga com as pessoas os processos espontâneos pelos quais respondem a uma interação. Este conhecimento se transforma para a construção de respostas mais úteis aos relacionamentos da pessoa.

Palavras-chave: Construcionismo social; Processos reflexivos; Terapia colaborativa-dialógica; Terapia de casal; Terapia familiar.

RESUMEN: El presente artículo describe experiencias en contexto de terapia dialógica colaborativa, que han instigado/ han tocado/han despertado mi curiosidad y creatividad. Sentimientos que me han inclinado a reflejar sobre mi práctica y buscar autores que me ayuden en el desarrollo de una descripción para lo que se volvió un concepto para el diálogo. Encontré en autores de las prácticas dialógicas las articulaciones que necesitaba para madurar lo que estaba sintiendo en la práctica. Responsividad Reflexivo es un concepto que investiga de manera conjunta los procesos espontáneos por los cuales las personas responden a una interacción. Este conocimiento se transforma para la construcción de respuestas más útiles a los relacionamientos de la persona.

Palabras clave: Construccionismo social; Procesos reflexivos; Terapia colaborativa dialógica; Terapia de pareja; Terapia familiar.

ABSTRACT: This paper describes experiences in the context of collaborative dialogical therapy, that touched my curiosity and creativity, feelings that made me reflect about my practice and seek authors to help me develop a description to what became a concept for dialogue. I found in the authors of collaborative practices the articulations that I needed to mature those feeling from my practice. Reflective Responsivity is a concept that investigates with people about the spontaneous processes through which they respond to an interaction. This knowledge transforms through the construction of more useful responses to the person's relationships.

Recebido em: 11/09/2019 Aprovado em: 05/03/2020
Keywords: Collaborative dialogical therapy; Couples therapy; Family therapy; Reflecting process; Social constructionism. 


\section{INTRODUÇÃO}

Neste artigo apresento a síntese de dois conceitos, desenvolvidos por dois autores proeminentes das práticas dialógicas, cito Responsividade, por John Shotter (2017a, 2017b, Shotter \& Katz, 1999) e Reflexividade, por Tom Andersen (1998, 2002, 2007a, 2007b). O estudo destes dois conceitos, somado às sensibilidades filosóficas da terapia colaborativa-dialógica (Anderson, 2007, 2009) e à teoria construcionista social (Gergen, 2017, McNamee \& Gergen, 1999), norteou minha prática clínica e o relacionamento com meus clientes.

Comprometido com a linguagem desta comunidade de autores e colegas, penso em uma proposta para a construção de conhecimento que esteja de acordo com a prática e entendimento dos relacionamentos humanos como situados e complexos, de tal forma que evitamos construir hipóteses a priori, sem que estas influenciem o desenvolvimento da relação. Portanto, o que se disponibiliza nessa linguagem é a descrição daquilo que interpretamos dos movimentos do nosso sentir em relação (Andersen, 2007a, 2007b). Por este motivo, o conhecimento aqui desenvolvido é produto de reflexões a posteriori com os clientes com quem senti os convites para os tipos de participação que vim a chamar de Responsividade Reflexiva.

Este conceito faz referência ao processo de fortalecimento de diálogo interno de uma pessoa (reflexividade) para que ela possa conhecer as respostas espontâneas que a interação imediata lhe evoca (responsividade). Ao conhecer as possibilidades de respostas espontâneas, a pessoa pode negociar consigo e experimentar na relação formas diferentes de ser com o interlocutor. Posteriormente, a pessoa avalia, tanto internamente, quanto externamente, quais participações desenvolvem o relacionamento em direções úteis e mutuamente generativas. Retornando ao processo de responsividade reflexiva para fortalecer os caminhos espontâneos mais socialmente úteis para ser com os outros, voltando, em seguida, à experimentação social. Num ciclo de respostas e reflexões, de diálogo interno e externo.

Ainda para contextualizar o leitor, é importante, para mim, que este conceito para a terapia não seja entendido como uma técnica, ou categorizado numa forma de fazer para o outro, com foco em resultados esperados pelo terapeuta. Esta forma de relacionar-se com o que apresentarei vai desumanizar um processo de estar com o cliente, quando minha expectativa é de responder aos sentimentos tocados no diálogo com a única e humilde intenção de aprender mais sobre o ser humano, cheio de potencial que nos procura como recurso para superação. Esta forma de estar com, que se afasta de um fazer para, é mais bem explorada em outras publicações (Anderson, 2007).

Nas próximas páginas apresentarei conceitos importantes para o entendimento da minha prática terapêutica, para, então, aprofundarmos os conceitos de Responsividade e Reflexividade.

\section{REFLEXIVIDADE}

Tom Andersen (1998) tinha um interesse especial pelas expressões corporificadas. Para o autor, linguagem é movimento. Toda expressão deve ter, portanto, um aspecto não verbal, no sentido que é performado pelo corpo e não usa palavras. Essas são respostas do corpo para algo que o tocou. Como terapeutas, podemos perguntar ao cliente o que ele viu, ouviu, ou sentiu, que fez seu corpo se expressar e o que há nesse algo em relação ao cliente e sua história. Esse tipo de pergunta oferece uma oportunidade de exploração das interações e sentimentos que evocam determinada resposta no cliente. 
O exercício proposto pela reflexividade é de estarmos sensíveis ao banal, para fazermos perguntas que buscam entendimento do nosso cliente, sobre aquilo que é espontâneo nele. Isso pode levá-lo a um movimento de pensar em si, de conversar consigo mesmo, sair do automático e entrar em reflexividade para entender aquilo que expressa sem pensar. É conversar com a sua experiência corporificada (Andersen, 2007a).

O autor propõe que, como terapeutas, sejamos tocados e respondamos àquilo que é falado, tanto verbalmente, quanto pelo corpo, por meio de descrições. Estas evitam as construções de hipóteses monológicas, que nos direcionam a uma interpretação do cliente, nos afastam da oportunidade de aprender com ele e deixá-lo explorar seu saber de si. Ele estimula que respondamos por meio da descrição, de repetir o que nos é dito e nos toca os sentimentos, para pedirmos por esclarecimento. Quando o cliente escuta o que disse, seja por se ouvir, seja pela descrição do terapeuta, ele pode refletir a interpretação de si e construir conhecimentos sobre seu funcionamento e possibilidades de tornar-se (Andersen, 2007a).

Além de terapeutas, somos humanos, também somos tocados e sentimos na interação. Sobre isso, Andersen reflete:

... quando a vida vem a mim, ela toca minha pele, meus olhos, meus ouvidos, os bulbos da minha língua, as narinas do meu nariz, como estou aberto e sensível para o que vejo, ouço, sinto, provo e cheiro, também posso observar as 'respostas' que emito a estes toques, quando meu corpo, desde seu interior, me faz saber por vários meios o que pensa sobre o que o toca no exterior, no que devo, no que não devo me concentrar. (Andersen, 1998, p. 70)

Este é um momento importante deste artigo, quando falamos do sentir e responder do terapeuta. Ao sermos tocados pelas palavras do cliente, é muito importante engajarmos nossa reflexividade, nosso diálogo interno, e nos fazermos algumas perguntas para construir uma resposta apropriada a um relacionamento terapêutico. Lenzi (2013) incentiva a reflexão quanto à resposta do sentir do terapeuta ser enunciada pelo personagem interno Terapeuta deste ser humano este conceito será mais bem desenvolvido adiante -, se refere às diferentes formas de ser que compõem nosso self e são performadas em interdependência com interlocutor e entorno. Uma resposta oferecida por outro personagem interno pode descaracterizar o acordo relacional estabelecido quando o cliente busca a nossa participação profissional. Qualquer exceção precisaria ser construída com o máximo de conhecimento, com muito diálogo interno, um tornar público sensível, humilde e atento ao diálogo externo e sentimentos do cliente.

Refletimos para responder às demandas locais de nossos clientes, abertos a nos tornarmos os terapeutas que eles esperam que sejamos, enquanto, simultaneamente, somos os terapeutas que refletem os riscos da posição de saber do outro para exercitar a simetria e o estar com em nome da autoria do cliente sobre seu processo (Anderson, 2009). Portanto, é crucial a reflexão do terapeuta para avaliação das respostas que lhe ocorrem; temos conhecimentos de uma vida de experiências, tudo isso é bem-vindo no diálogo, contanto que, nesta avaliação, fique evidente que a voz que oferece uma experiência é a voz do personagem interno Terapeuta. Alguns formatos principais podem facilitar o compartilhamento seguro de experiências, sendo a pergunta conversacional minha preferência. Quando somos tocados por um conteúdo (seja por mobilizações corporais, emocionais, de identificação, ou curiosidade etc.) nos engajamos em diálogo interno para entender o que nos mobilizou ali, qual o nosso entendimento daquilo e como podemos fazer uma 
pergunta ao outro que convide o seu entendimento, para que possamos estar mais próximos dos significados do cliente, enquanto abrimos nossos próprios para questionamento e reflexão. Outras formas seriam: testemunhos, reflexões, convites a testemunhas externas, cartas testemunhais.

\section{RESPONSIVIDADE RELACIONAL}

Quando respondemos à interação, nossas ações pertencem parcialmente a nós, por meio do diálogo interno e reflexividade, mas parcialmente ao outro, que influenciou nossa resposta com a sua oferta anterior. Vivemos num continuum responsivo desde que nascemos, sempre agregando complexidade à interação, mas sempre partindo de uma resposta anterior (Shotter \& Katz, 1999). Dessa forma, se pensarmos o entorno da terapia, nossas respostas continuam influenciando a responsividade do cliente; isso é a base de acreditarmos nas transformações por intermédio dos relacionamentos. Shotter e Katz (1999) intensificam a atenção a esse fluxo e entendem que estamos nos relacionando com toda a historicidade de quem encontramos no diálogo; passamos a pertencer a um grande organismo relacional. Estes autores convidam a nos afastarmos de noções de separação, de self independente e do individualismo. Afirmam que o que um de nós faz depende do que todos nós estamos fazendo. Responsividade relacional é a mistura de tudo o que eu vivi em minha história, com tudo o que me rodeia e passa a me compor, para construir a resposta enunciada à interação.

Podemos entender que as respostas das pessoas têm muito amparo sócio-histórico e isso é mais um apelo ao terapeuta que legitima essa complexidade ao iniciar sua participação como algo que rodeia a pessoa. Acredito que uma participação que respeita esse organismo relacional pode ser mais efetiva que participações que não estão atentas à alteridade situacional.

Responsividade é construída e ganha força de espontaneidade por meio da suplementação social. Toda resposta que oferecemos foi historicamente suplementada por comunidades de inteligibilidade (pessoas significativas, entendimentos grupais e culturas) e continua sendo suplementada cada vez que, em uma interação, oferecemos um determinado itinerário de respostas, ao qual nossos interlocutores respondem de forma a suplementar nossa resposta, conferindo significado através desta ação. Nas palavras de Gergen: "nenhuma das palavras contidas em nosso vocabulário têm significado em si mesmas. Elas ganham a capacidade de significar em virtude do modo como elas são coordenadas com outras palavras e ações" (Gergen, 2017, p. 124). De outra forma, nada possui significado até ser suplementado por um interlocutor. Até mesmo em nossas conversas internas, quando falamos e escutamos a nós mesmos, muitas vezes nos surpreendemos com o tom com o qual enunciamos e suplementamos a nós mesmos de formas variadas.

Pensando que não há ação significativa em si, que todo enunciado depende de um interlocutor para ser significado, entendemos as comunidades de inteligibilidade como os limites linguísticos que circunscrevem nossos enunciados de forma a facilitar entendimento e suplementação. Se nos retiramos dessa fronteira, estamos encerrando a interação. Como terapeuta, estou atento a essas comunidades, suas tradições, sua linguagem, para respeitar os limites locais, em ordem a participar da produção de significados locais, úteis aos envolvidos nas futuras suplementações daquilo que aparece no processo. Uma participação não sugestiva evita riscos de reflexões em que o cliente não tem autoria sobre. Sugestões podem não perceber a legitimidade social, um diferente demais, como Andersen (2002) relata, pode 
causar estranheza nos relacionamentos para os quais o cliente volta após a sessão e um esforço relacional de manter a configuração atual dos relacionamentos. A prática colaborativa visa justamente à legitimação da multiplicidade de saberes para que os resultados respeitem a todos os envolvidos e gerem compromisso com as construções sobre as quais todos sentem autoria e participação.

Conversações dialógicas são o meio pelo qual nos desenvolvemos e ao nosso mundo; nem toda troca é dialógica, mas naqueles momentos em que as alcançamos, encontramo-nos com o potencial de transformação duradoura dos significados. Como desenvolvido por Shotter (2017a), um momento interativo ocorre quando pessoas criam uma conexão viva através da escuta e respostas espontâneas. Toda resposta carrega expectativas para a resposta do outro; ao mesmo tempo, as respostas que recebemos só têm coerência naquela interação, elas são construídas sob medida a nós. Não quero correr o risco de que o leitor entenda que é possível controlar as respostas dos outros através das nossas. Na verdade, não conseguimos nem ao menos controlar nossas próprias respostas. Nunca temos acesso total a como estamos respondendo às interações, isso porque nossa resposta só finaliza quando ela é significada pelo interlocutor, permeado por sua própria história de vida e linguagem. O que podemos ter é o entendimento produzido da escuta e da reflexão sobre as possibilidades de respostas espontâneas. Construímos então nossos enunciados com expectativas de respostas diferentes pelo interlocutor, que serão avaliadas apenas após sua significação e consequente resposta, para retomar a reflexividade e continuidade do relacionamento até que haja entendimento mútuo.

\section{SELF RELACIONAL}

Podemos entender mais desse conceito com a compreensão de self relacional (McNamee \& Gergen, 1999) e personagens internos (Lenzi, 2013) do construcionismo social. Este entendimento faz referência aos processos sóciohistóricos que nos desenvolveram em quem somos. Os relacionamentos mais relevantes da nossa experiência criam roteiros, itinerários, por onde as pessoas entendem umas às outras e oferecem suas respostas. Desta forma, quando, em um relacionamento, nos remetemos a itinerários historicamente suplementados de ser e estar com os interlocutores, que sentimos como coerentes a esta relação situada. Respondemos de forma semelhante a interações que nos fazem sentir como em outros relacionamentos já vividos. Estas trocas, vividas ao longo do tempo, muitas vezes são avaliadas como úteis àquelas interações e se tornam responsividade espontânea às pessoas no diálogo (Shotter, 2017b). Mas a repetição das respostas historicamente fortalecidas pode levar a interações menos qualitativas em determinados momentos. Em terapia, escuto atentamente por vozes, ou respostas, alternativas as mais espontâneas que o cliente tem disponível em seu self, e busco entender a multiplicidade de alternativas imaginárias às suas expressões. Quando percebemos formas diferentes de ser e responder a interações, podemos iniciar perguntas que buscam entender aquelas personagens performadas pelo outro, caracterizando-as em vozes internas, ou personagens internos. Quando complexificamos o self podemos experimentar maior reflexividade - através do diálogo interno que o cliente estabelece com as diferentes formas de ser que vem a conhecer no diálogo e que podem ser performadas nas interações -, que constrói respostas com mais conhecimento do que uma situação pede, e quais os resultados preferenciais para aquela interação. Personagens internos aparecem em diferentes

Nova Perspectiva Sistêmica, v. 29, n. 66, p. 22-35, abril 2020. 
contextos, com diferentes pessoas. São roteiros que seguimos espontaneamente, que podemos nomear para ter mais conhecimento sobre o situacional que nos evoca um personagem e também recursos para manifestações alternativas (Lenzi, 2013). Alguns já caracterizados em mim são: o terapeuta; o general (que cobra e exige através da culpa); o Aprendiz (que desarma o general através do compromisso com a aprendizagem de cada situação), entre muitos outros. Esses nomes foram escolhidos por mim na minha busca por eles, diferentes pessoas buscam e encontram diferentes personagens e nomes para se relacionarem com eles.

\section{PERGUNTAS CONVERSACIONAIS}

Toda resposta que ofereço em diálogo é norteada por meu interesse em entender toda a complexidade da experiência. Enquanto escuto meu interlocutor, faço perguntas para verificar meu conhecimento, essas perguntas esforçam o saber do cliente-instrutor, que se empodera enquanto maior conhecedor da situação que vivencia. Anteriormente estas perguntas foram chamadas de perguntas conversacionais (Anderson, 2009; Anderson \& Gehart, 2007).

Estas buscam, exploram e desafiam conhecimentos. Em minha prática, são perguntas que começam com "o quê", quero conhecer a apresentação mais espontânea do cliente; exemplos são: "o que é mais importante eu saber?”; "o que aconteceu?”; “o que significa isso?”; “o que responderam?”. Quando ouço esta apresentação, frequentemente conheço alguns participantes da história, então começo a perguntar "quem?" - exemplos: "quem é você, para além do problema, em toda a sua complexidade?"; "quem são estes participantes?"; "quem é você nesta situação?"; "quem participa, mas não apareceu no relato?"; "quem poderia participar? E o que aconteceria de diferente?". Neste último exemplo evidencio que as perguntas não acontecem linearmente, mas de forma responsiva ao relato, novos conhecimentos convidam novas perguntas, construídas com a única intenção de entendimento.

De forma semelhante, quando outros participantes não podem estar conosco presencialmente, uso de cartas para conhecê-los, ou quando mesmo isso se torna inacessível, convido a voz internalizada deste no meu cliente para entender uma possível descrição alternativa, "você fala dessa pessoa como alguém íntimo e bastante relevante na história. Se ela estivesse aqui, conosco, o que ela teria a contar? Como ela responderia à escuta da sua narrativa?".

O entorno físico, como também o entorno subjetivo, é outro participante que estou interessado em conhecer. Afinal, diálogo ocorre nas trocas linguísticas entre interlocutores, inseridos em um contexto que legitima responsividade (Shotter, 2017a) e personagens internos específicos (Lenzi, 2013). Ocorrem-me perguntas como: "onde estavam nesta situação?"; "onde ocorrem estas situações?"; "onde você encontra com o seu problema?"; “onde o problema não consegue alcançá-lo?”; "onde vocês têm uma interação diferente?"; "onde você acredita que estará quando as coisas forem diferentes?". Perceba, leitor, que outra forma como construo minhas perguntas é através da articulação do tempo. Perguntas que remetem ao passado, presente e futuro convidam à construção de saberes complexos, para além do momento em que a experiência se caracteriza como problema. Alguns exemplos: "quem é você hoje?"; "o que aconteceu nessa situação? E o que será diferente na próxima vez?"; “onde estavam/estão/estarão quando nessa interação?"; "quem foi/é/ poderá ser participante?”. 


\section{RESPONSIVIDADE REFLEXIVA}

A união destes conceitos ocorre quando terapeuta e cliente(s) se engajam na exploração de uma determinada interação problemática. Através de reflexividade, exploramos a historicidade e coerências socialmente suplementadas para aquela responsividade espontânea. Então passamos a imaginar respostas criativas einovadoras àqueles itinerários relacionais e suas repercussões sociais. Investimos conhecimento reflexivo nessas cenas imaginárias, exploramos, a partir do conhecimento local, as formas como interlocutores poderiam responder. Criamos espaço no diálogo interno para a percepção das respostas disponíveis ao cliente. Então ele parte para a prática relacional em seu cotidiano quando experimenta respostas refletidas para diferentes interlocutores, em diferentes entornos. Neste momento inicia a reflexão sobre a qualidade interativa das respostas performadas, para seu fortalecimento no self do cliente. Isso é feito em diálogo interno e externo, com seu terapeuta e com quem mais tiver participação íntima no processo. Essas trocas suplementam uma responsividade refletida em direção à corporificação. Esta passa a se tornar uma responsividade espontânea ao cliente.

São perguntas de Responsividade Reflexiva as perguntas que buscam entender o ocorrido e as possibilidades de ocorrer para uma melhor avaliação. A partir da exploração do espontâneo, o cliente constrói alternativas mais atuais (úteis) às futuras interações (Shotter, 2017b). Pela prática suplementar no cotidiano dos relacionamentos que evocam tais respostas, num processo de tentativa e reflexão, avaliação e nova tentativa, elas são incorporadas ao repertório de respostas espontâneas. Em suma, nada é espontâneo, natural, ou automático, se não for praticado em interações que respondem de forma a legitimar tal enunciado, a ponto de sua expressão ocorrer sem intenção. "O que você respondeu nesta situação?"; "o que gostaria de ter respondido?"; "em que contextos você consegue responder diferente a um convite semelhante?"; "como outros participantes respondem?"; "que participantes facilitam respostas diferentes em você?"; "o que dá coerência (qual a utilidade histórica social) para esta resposta espontânea?"; "quais diferentes respostas você tem?"; "como preparar o terreno para a expressão de uma resposta desejada?”. Estas são perguntas que visam, comojá explicado anteriormente, à produção de conhecimento sobre as respostas espontâneas do cliente, que possam ser atualizadas a partir da construção de conhecimento da situação. Na prática, o cliente passa a experimentar, tanto na imaginação, quanto nas interações ao vivo, reflexões para um processo mais qualitativo de construção da sua forma de ser com outrem.

\section{EXERCÍCIO DE RESPONSIVIDADE REFLEXIVA}

Proponho um exercício aos colegas terapeutas, para momentos em que a interação gera um sentimento no terapeuta, com a esperança de oferecer interpretações mais qualitativas ao relacionamento e respostas criativas às vicissitudes interacionais. O objetivo é oferecer reflexão quanto à responsividade dos terapeutas frente a conteúdos que os evocam personagens internos diferentes do Terapeuta, quando no atendimento aos seus clientes.

- Lembrem de uma situação recente que os fez viver um sentimento marcante;

- Sintam esse sentimento e se perguntem o que estão sentindo, deem nome a este sentimento;

Nova Perspectiva Sistêmica, v. 29, n. 66, p. 22-35, abril 2020. 
- Em seguida, reflitam sobre quando sentiram algo semelhante, imaginem esta história passada e permitam-se serem transportados para esta cena em suas imaginações;

- Quando tiverem desenvolvido os detalhes dessa cena vivida, prestem atenção em quem eram vocês nessa cena, desenhem este momento da sua vida, desenvolvam esta voz interna em um personagem interno, alguém que vocês já foram no passado, que encontraram no presente através da imaginação;

- Agora construam em detalhes um personagem interno que vou chamar de Terapeuta, mas cada um pode ter um nome diferente para esta voz no self, experimentem nomear o seu a partir de sua história de vida;

- Com o personagem do passado e o Terapeuta desenvolvidos, coloquem-nos em conversa sobre a experiência que causa aquele sentimento da situação recente. Perguntem-se se o sentimento recente e o sentimento histórico são realmente os mesmos. Detalhem a apreciação das singularidades e diferenciem-nas;

- Construam uma resposta desejada para a situação histórica e reflitam se essa resposta também seria válida na situação recente, ou que resposta estes personagens internos poderiam construir para avaliarem como a melhor forma de tomar parte na situação presente, comprometam-se em legitimar as sugestões de ambos os personagens internos, aquele encontrado na história e o Terapeuta;

- Com algumas respostas construídas no diálogo reflexivo, experimentem as interações que manifestam os sentimentos recentes e voltem a esse exercício sempre que precisarem avaliar a espontaneidade manifesta num relacionamento.

Após essa conversa, podemos oferecer aos nossos parceiros conversacionais nossa história pessoal, ou uma pergunta que torne público esse exercício interno, com a única intenção de estimular a intimidade no diálogo, um saber de si e do outro, para a construção de continuidade mutuamente engrandecedora.

Esse exercício nos afasta da simplificação das interações, nos colocando para refletir quanto à espontaneidade das nossas respostas e construção de novas em diálogo interno. Andersen reforça este apelo quando descreve sua prática como um relacionamento que oportuniza às pessoas "verem o que elas têm nelas mesmas e o que há ali” (2007b, p. 171), enquanto critica as práticas que acreditam que "devem treinar ou ensinar as pessoas" (p. 171). O convite é por nos afastarmos do centro da terapia enquanto centralizamos a linguagem do cliente; há conteúdo e conhecimento suficientes para serem explorados ali.

Os próximos parágrafos exploram algumas interações com clientes que viveram processos de responsividade reflexiva em minha prática clínica.

\section{REFLEXÕES DESDE A PRÁTICA}

Com um cliente, na terceira sessão de seu processo conversávamos sobre seu desempenho universitário e um pensamento constante do que ele deveria fazer, mas não dava conta, uma voz que cobrava incessantemente a resolução de seus problemas. Esta voz aparecia em diversos momentos do seu dia, enquanto se exercitava, enquanto comia, escovava os dentes e outros. Antes de assumir que essa voz era um

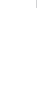


problema, eu estava curioso para conhecer sua história com o cliente. Pedi para ouvir mais sobre essa voz. Ele descreve que já foi uma voz coerente, ajudando-o a resolver complexas equações matemáticas enquanto fazia outras atividades. Perguntei sobre as atividades às quais ela se engaja hoje. Havia ficado claro que ela não estava mais aparecendo em momentos que ajudavam, mas que causavam desconforto. Ele descreve atividades sociais, preparação para entrevistas de emprego, contextos nos quais ele sente que não há aproveitamento dessa voz e que quando ele se concentra no que está fazendo; se distraindo dessa voz ao perceber a si e seu entorno, ele consegue não se cobrar e desempenhar melhor a atividade em que está engajado, desde escovar os dentes, até sua organização para a universidade. Perguntei sobre essa resposta, de estar concentrado na atividade em ação. Ele diz que é focar, que na verdade não havia pensado nada daquilo antes, mas que, parando para pensar, quando consegue evitar essa voz através do exercício de focar na atividade, sente seu desempenho mais qualitativo. Escuto animado com a reflexão quanto às respostas disponíveis. Ele finaliza me contando que uma coisa é pensar ali, comigo, outra é conseguir praticar. Perguntei se já está praticando, ele confirma, então disse que isso me faz sentir tranquilo com o foco que vem exercitando, um recurso pessoal dele, que surge nas conversas comigo e ganha espaço, e força, no seu dia a dia. Nas sessões seguintes, percebemos juntos que, a cada avaliação de sua prática, o esforço se tornava menor. Minha reflexão é que a interação comigo foi suplementadora da reflexão para a resposta de focar na atividade.

Este é um breve exemplo de como um processo com responsividade reflexiva começa pelo conteúdo do cliente. O terapeuta colaborativo-dialógico evita sugerir respostas. Para nós, o novo é entendido como mais útil ao cliente, como um resultado feito sob medida e duradouro, quando é construído desde e através da linguagem do cliente para que a suplementação seja do recurso local, não de uma intervenção terapêutica, que poderia alienar seu processo no meu saber. Nosso interesse inicial é pelas respostas que ele já oferece às situações desafiadoras, mesmo que avaliadas como disfuncionais. É importante que o terapeuta tenha curiosidade para conhecer o processo sócio-histórico do desenvolvimento dessa resposta em detalhes; que pergunte sobre os sentimentos que são tocados, das interpretações que faz, das memórias que são evocadas, de como já respondeu a situações semelhantes. Algumas vezes uma resposta que o cliente avalia como preferencial é descrita como um momento de exceção, de um entorno em que reagiu surpreendentemente, ou de participantes que facilitaram outras respostas. Outras vezes, quando esgotamos nossa investigação quanto às respostas disponíveis, podemos perguntar o que ele gostaria, ou o que ele não gostaria de responder em futuras situações semelhantes. Aí é quando a sensibilidade do terapeuta entra em ação para verificar como os entornos influenciarão a interação e como participantes responderão em diferentes entornos, sejam eles internos ou externos. São perguntasque convidam à descrição dessa resposta diferente, que convidam a uma complexificação para entendermos quando, onde e com quem ele tem acesso a isso. Interessados por o que facilitaria e o que dificultaria a resposta preferencial. Pelo personagem interno que pode ser convidado para refletir com aquele que tem a resposta mais espontânea, sócio-historicamente suplementada, e como negociar espaço para tentativas, através de legitimação histórica e reflexão quanto ao futuro preferencial para as formas de ser em interações. Como terapeuta, não prescrevo exercícios, busco desenhar com o máximo de definição as cenas em que essas respostas serão evocadas, para que esta conversa facilite reflexão e testagem no cotidiano do cliente. Quando solicitado pelo cliente, convido nosso engajamento mútuo e simétrico para a construção de um exercício que legitime recursos que já reconhece em si, enquanto propõe o novo manifesto no diálogo em sessão. Na próxima vez em que o cliente escolher conversar

Nova Perspectiva Sistêmica, v. 29, n. 66, p. 22-35, abril 2020. 
sobre essas respostas, podemos avaliar juntos a reflexão do momento responsivo para suplementar ainda mais os personagens internos que responderão com mais qualidade à interação problematizada nas próximas oportunidades.

\section{ENTREVISTA COM UMA CLIENTE MESES APÓS SEU PROCESSO}

Para ilustrar mais uma experiência prática com o conceito de responsividade reflexiva, identifiquei um processo terapêutico em que o conceito foi espontaneamente exercitado ao longo das sessões que tivemos juntos. Solicitei a essa cliente uma entrevista, onde iniciei com uma apresentação do conceito e desejo de produção do artigo. Posteriormente, pudemos compartilhar lembranças e reflexões acerca da sua percepção de novas respostas se manifestarem, uma vez que exploramos a responsividade espontânea em algumas de suas relações. Ela aceitou que essa conversa e seus conteúdos fossem utilizados no artigo.

Minha primeira curiosidade vinha da relação com sua mãe, mais especificamente de alguns momentos de desencontro. Relembrei de uma sessão nossa, quando explorávamos, na imaginação, uma futura interação mãe e filha. A riqueza do conhecimento e detalhes era tamanha que comecei a pensar que estávamos falando de uma situação passada. Eu havia perguntado se uma reação de sua mãe, descrita pela cliente, era uma previsão que fazia em diálogo interno com sua mãe internalizada historicamente em seu self, ou se era um relato da situação vivida recentemente em diálogo externo. Naquela sessão ela havia me dito que aquela era a conversa com a mãe interna, que ainda não havia tido a conversa externa, porque sabia como a mãe reagiria. Enquanto eu lembrava a cliente do momento em que eu gostaria de levá-la para ouvir suas reflexões, destaquei uma lembrança de uma pergunta curiosa que me ajudou muito a entendê-la naquela interação. Esta foi uma pergunta sobre sua mãe internalizada e sobre quem era ela na relação com a mãe internalizada, algo no sentido de quantos anos tinham mãe e filha nessa interação interna, na situação. Ela respondeu algo que a remetia à infância, momentos marcantes da interação com a mãe ao longo da história, que davam coerência para aquela mãe internalizada que ela trazia consigo. Foi quando fiz algumas perguntas para saber mais do seu desenvolvimento desde então, queria entender se, na relação com a mãe, ela voltaria a ser aquela criança e também se - e quando e onde - tinham interações diferentes. Deste desenrolar da conversa que, ao final da sessão, perguntei o quão certa ela estava da atualidade da versão de sua mãe interna, ela disse algo como não estar bem certa, mas que descobriria.

Relatei essas memórias para minha cliente, nesta recente conversa que tivemos para desenvolver este texto. Ela ainda complementou com cenas posteriores àquela sessão. Que desde então reflete sobre a participação do entorno no diálogo com a mãe, que sua cama, com ambas sentadas juntas, tem se apresentado como um excelente espaço para escuta, entendimento e resposta - enquanto que, quando inseridas nas atividades domésticas de limpeza da casa, o solo é fértil para discussões e conflito. Essa reflexão expressa de forma clara e simples a participação do entorno na manifestação do self dos envolvidos. O lugar físico, assim como o contexto emocional, é cenário para a evocação de personagens internos e das respostas historicamente preparadas para situações similares.

Ao me engajar na curiosidade para entender o entorno, os personagens e as respostas que estavam sendo oferecidos à relação, acompanhei a cliente em suas reflexões sobre o que era espontâneo nesta interação e a suplementação histórica para esta espontaneidade. Após ouvi-la atentamente e fazer perguntas para entendê-la, tornei

Nova Perspectiva Sistêmica, v. 29, n. 66, p. 22-35, abril 2020. 
pública minha surpresa com relação aos conhecimentos que a cliente tinha de quem eram ela e a mãe, quando juntas. Iniciamos uma reflexão quanto aos conhecimentos que existiam, mas não estavam sendo legitimados nas respostas que apareciam na interação com a mãe. Foram detalhes históricos, esquecidos no cotidiano, que pudemos encontrar e convidar para uma participação mais democrática na interpretação da interação problematizada. Esse conhecimento novo, construído no diálogo - nossa conexão viva - que faz diferença na interpretação que o cliente tem do mundo à nossa volta e sua descrição para a interação, pode ser entendido como um momento interativo (Shotter, 2017a). O contato com o conhecimento, o exercício de entender as histórias por trás de uma resposta, dos sentimentos que são tocados para evocar determinados personagens, levaram a cliente à reflexão quanto às suas respostas. Ela pôde explorar os lugares para onde era levada nessa interação, os lugares onde não gostaria de voltar a ir. Concluímos que isso a preparou para, no próximo encontro com sua mãe, estar mais atenta àquilo que está acontecendo no presente e os ganchos que podem rebocá-la ao passado.

Este trecho me leva a pensar em Andersen (2002), quando ele reflete sobre a importância de deixar de generalizar e de atribuir características situacionais à personalidade da pessoa. Em um movimento de nos afastarmos de descrições essencialistas das pessoas, o autor propõe um exercício de tempo e espaço ao descrevermos uma pessoa. Isso significa situar o comportamento expresso pela pessoa que será descrita na - como pertencente a - interação, diferentemente da descrição que situa o comportamento na identidade da pessoa, como, por exemplo: dizer que alguém é grosseiro. Esse movimento coloca complexidade no aspecto relacional das formas como somos e nos tornamos em relação, possibilitando encontros com novas formas de ser das pessoas, quando o contexto e os participantes são considerados para a expressão do self. Ainda no exemplo da pessoa descrita como grosseira, uma descrição como essa simplifica a pessoa nessa manifestação relacional, ignorando a historicidade dos envolvidos e a suplementação oferecida pelos participantes e entorno (tanto físico, quanto emocional) da situação. A influência do entorno, o diferente que nos invade e evoca formas de ser, também foi chamado de alteridade situacional por Shotter (2017b). Ao descrevermos uma pessoa relacionalmente, podemos dizer que eu interpretei a pessoa como grosseira comigo em determinada situação. Podemos ainda contextualizar nosso relacionamento histórico com a grosseria, destacando interações semelhantes situadas no passado, que facilitam a interpretação que faço da pessoa no presente e os contextos em que estava inserido que facilitaram esse sentimento, refletindo as alteridades presentes que participam sutilmente das interpretações que faço do mundo à minha volta. A proposta dessa linguagem é de oferecermos uma percepção menos individualista das pessoas, além do potencial de experimentarmos uma resposta nova de nosso interlocutor, uma vez que este não está mais reduzido a uma identidade essencialista, ou fechada, mas sendo descrito a partir do que estamos entendendo do que está acontecendo no momento e a partir da história da interação, enquanto convidando o outro para verificar nosso entendimento e ambos para alinhar respostas mais úteis à manutenção do relacionamento.

\section{POSIÇÕES REFLEXIVAS FACILITADORAS DE RESPONSIVIDADE REFLEXIVA}

A seguir apresentarei como posições reflexivas - formas diferentes de ouvir e responder - dos participantes de um diálogo podem favorecer a responsividade reflexiva, que facilita novas escutas e novas respostas. O exercício aqui

Nova Perspectiva Sistêmica, v. 29, n. 66, p. 22-35, abril 2020. 
é experimentar novas formas de nos relacionarmos com o comum, curiosos para como essas experiências evocam respostas diferentes em nós mesmos e nos clientes. Então exploramos essa novidade para enriquecer sua complexidade e produzir conhecimento para sua manifestação espontânea nos relacionamentos cotidianos das pessoas interessadas.

As posições reflexivas podem ser entendidas como presentes em todo diálogo, mas podem ser mais bem aproveitadas quando exploradas pelos participantes, quando exercitadas em consonância ao conceito de responsividade reflexiva. Faço referência a Tom Andersen (2002), quando ele oferece a possibilidade de convidar os participantes presentes em uma sessão de terapia, para ouvirem os outros presentes sem responder - ou interromper - à interação entre um deles e o terapeuta, facilitando uma posição de escuta comprometida com o silêncio e plena expressão do falante. Essa fala não interrompida pode oferecer ao narrador uma resposta diferente, uma vez que este sabe que poderá se expressar livremente até finalizar. Ao mesmo tempo, o ouvinte, na posição reflexiva, pode ouvir um conteúdo já conhecido de forma inovadora.

$\mathrm{Na}$ prática, quando atendo a uma família, ou casal, ou mesmo um grupo de pessoas, eu explico que às vezes as pessoas presentes no encontro, por já estarem demasiadamente inseridas, ou saturadas, no dia a dia do assunto, podem cair em conversas conflituosas e já conhecidas a elas. A estrutura que ofereço pode facilitar uma conversa diferente para pensarmos de forma criativa nos problemas e relacionamentos. Peço para conversar com um de cada vez e que o outro apenas escute, sem interromper, mesmo que não concorde ou que queira complementar o relato do falante. Reforço que pode ser difícil ouvir algum conteúdo que causa desconforto ou dor. Se isso acontecer, eu incentivo a pessoa que está na posição reflexiva a sair da sala para tomar um copo d'água, ou de café, ou apenas para não ouvir determinado conteúdo, e que volte quando se sentir confortável. Mas peço que não nos interrompa; a pessoa com o desconforto não precisa ouvir algo desconfortável, mas eu preciso ouvir e entender cada um deles ao máximo que eu conseguir. Depois do combinado feito, se alguém tenta interromper, eu reforço o combinado feito anteriormente.

Comecei a fazer este convite após alguns clientes espontaneamente saírem da sala ao ouvirem o outro (às vezes em rompantes emocionais) e entendi que este era um importante recurso para oferecer antes do rompante, para garantir espaço de expressão legítima a todos os participantes. Volto a fazer referência a Andersen (2002), que acreditava na expressão sem interrupção de seus parceiros conversacionais. Se as pessoas tornam-se na linguagem, então a interrupção de uma expressão limita suas possibilidades de ser. Simultaneamente, lembro do caso relatado por Tom, que sentiu que deveria ter interrompido um filho que falava de sua mãe, também presente. Isso custou ao terapeuta a continuidade do processo e causou uma mágoa da mãe para com Tom, fato confirmado pelo filho, meses após o momento fatídico. Desta história pude refletir que não falamos de regras para fazer terapia, mas de sensibilidades para estar com (Lenzi, 2017). Se sentimos que precisamos interromper, é nossa responsabilidade refletirmos para a construção qualitativa dessa resposta. É importante que ofereçamos espaço de plena expressão aos clientes, enquanto garantimos que quem escuta, escuta se estiver confortável.

O conceito de posições reflexivas facilitadoras de responsividade reflexiva também pode ser performado quando temos uma dupla de terapeutas no atendimento. A dupla pode combinar entre si e com o cliente que um deles apenas ouvirá a conversa e, posteriormente, compartilhará reflexões a partir da escuta. Muito semelhante a uma equipe reflexiva de uma só pessoa. Ainda outra possibilidade 
aos terapeutas é pedir que o(s) cliente(s) apenas escutem por alguns minutos a conversa entre a dupla de profissionais a partir daquilo que ouviram e entenderam dos relatos oferecidos pelos clientes. Isso é um recurso útil para os terapeutas se encontrarem, ao tornarem públicas suas conversas internas e construírem juntos a pergunta que gostariam de oferecer para a continuidade do relato do cliente, ou clientes.

Para exemplificar uma prática, recentemente uma dupla de colegas convidou a uma estrutura de posições reflexivas um casal que vinha tendo certa dificuldade de engajar em conversações dialógicas. Combinaram que uma delas conversaria com um dos cônjuges, enquanto a outra apenas ouviria junto ao outro cônjuge para, posteriormente, conversarem sobre a conversa que escutaram e o que mais fosse importante para aquele momento. Ambas as terapeutas me relataram a surpresa delas mesmas e do casal, em conseguirem se ouvir de forma respeitosa e segura, uma vez que cada cônjuge estava acompanhado de uma terapeuta para garantir seu espaço de expressão.

\section{REFLEXÕES FINAIS}

Responsividade Reflexiva é um conceito que investiga com as pessoas os processos espontâneos pelos quais respondem a uma interação. Através do conhecimento dos sentimentos mobilizados e histórias associadas, podemos exercitar reflexividade, ou diálogo interno, para a construção de respostas alternativas às espontâneas. Como Shotter (2017b) desenvolve em seu trabalho, podemos entender o espontâneo como aquilo que foi muito treinado na história dos relacionamentos da pessoa. Temos, com este conceito, a oportunidade de tornar espontâneas novas respostas através da suplementação social.

O diálogo tem muitas formas. Cabe a nós, terapeutas colaborativos-dialógicos, a construção de possibilidades que facilitarão esse tipo de conversa para as pessoas que nos buscam com problemas. Estamos todos produzindo conhecimento com nossos clientes; conhecimento que merece ser compartilhado com a comunidade. Quando refletimos o que vem acontecendo em nossos encontros conversacionais, as respostas que nos têm ocorrido, podemos ter mais entendimento de quem somos como terapeutas. Podemos ter mais curiosidade para investigar os princípios filosóficos que são subtexto das nossas respostas. Comprometo-me a desapegar da minha húbris, em achar que posso ensinar qualquer coisa a alguém. Volto a uma forma humildemente interessada em aprender com o mundo à minha volta, sobre como ser um bom participante. Anderson (2009) já dizia que não podemos ensinar nada a ninguém, mas podemos facilitar um espaço e relacionamento que convide à aprendizagem singular de cada participante interessado no processo.

O conceito de responsividade reflexiva é um convite antigo, explorado de forma nova, como um exercício de si mesmo. Se podemos pensar nos nossos repertórios como humanos terapeutas de forma criativa, podemos construir novas respostas às interações com nossos parceiros conversacionais. Sempre estamos respondendo a uma resposta anterior. Em um momento oportuno podemos refletir, responder internamente com nossos personagens internos para conhecermos a nós mesmos na interação. Este conhecimento ampliará as possibilidades de tornarmo-nos no relacionamento. Quando nos tornamos algo novo, convidamos o interlocutor ao novo e criativo. A responsividade reflexiva é mais um momento marcante, um momento generativo, um suficientemente diferente, no diálogo colaborativo. Tenho esperança de que o meu compartilhamento convide respostas e outros compartilhamentos para a continuidade desta conversa. 


\section{REFERÊNCIAS}

Andersen, T. (1998). Reflexões sobre a Reflexão com as Famílias. In S. McNamee \& K. J. Gergen (Orgs.), A Terapia como Construção Social (pp. 69-85). Porto Alegre: Artes Médicas.

Andersen, T. (2002). Processos reflexivos (2a ed.). Rio de Janeiro: Noos.

Andersen, T. (2007a). Human Participating: Human "Being" Is the Stepfor Human "Becoming" in the Next Step. In H. Anderson \& D. Gehart (Eds.), Collaborative Therapy: Relationships And Conversations That Make a Difference (pp. 81-94). London: Routledge.

Andersen, T: (2007b). In Conversation with Per Jensen: Crossroads. In H. Anderson \& P. Jensen (Eds.), Innovations in the Reflecting Process (pp.158-174). London: Karnac Books.

Anderson, H. (2007). The Heart and Spirit of Collaborative Therapy: The Philosophical Stance - "A Way of Being" in Relationship and Conversation. In H. Anderson \& H. Gehart (Eds.), Collaborative Therapy: Relationships And Conversations That Make a Difference (pp. 43-59) London: Routledge.

Anderson, H. (2009). Conversação, linguagem e possibilidades: um enfoque pósmoderno da terapia. São Paulo: Roca.

Anderson, H.\& Gehart, D. (2007). Collaborative therapy: conversations and relationships that make a difference. New York: Routledge.

Gergen, K. J. (2017). Construção Social e Comunicação Terapêutica. In M. Grandesso (Ed.), Práticas Colaborativas e Dialógicas em Distintos Contextos e Populações: um diálogo entre teoria e práticas (pp. 143-166). Curitiba: CRV.

Lenzi, T. P. (2013). Personagens internos. Nova Perspectiva Sistêmica, 47, 86-98.

Lenzi, B. (2017). O fazer e o estar em terapia dialógica colaborativa. Nova Perspectiva Sistêmica, 57, 37-52.

McNamee, S. \& Gergen, K. J. (1999). Relational Responsibility. Resources for sustainable dialogue.Thousand Oaks, CA: SagePublications.

Shotter, J. \& Katz, A. M. (1999). Creating Relational Realities: responsible responding to poetic 'movements' and 'moments'. In S. McNamee \& K. J. Gergen(Eds.), Relational Responsibility. Resources for sustainable dialogue (pp. 82-98)> Thousand Oaks, CA: Sage Publications.

Shotter, J. (2017a). Momentos de referência comum na comunicação dialógica: uma base para colaboração clara em contextos únicos. Nova Perspectiva Sistêmica, 57, 9-20.

Shotter, J. (2017b). Realidades Terapêuticas e o Diálogo: corpo, sentimentos, linguagem e mundo. In M. Grandesso (Ed.), Práticas Colaborativas e Dialógicas em Distintos Contextos e Populações: um diálogo entre teoria e práticas (pp. 143 166). Curitiba: CRV.

\section{BRUNO LENZI}

É terapeuta colaborativo-dialógico, coordenador do Programa de Treinamento em Práticas Colaborativas e Dialógicas do Instituto Movimento, Florianópolis, associado honorário ao Taos Institute, Chagrin Falls, Ohio, EUA.

https://orcid.org/0000-0002-1024-4004

E-mail: brunoplenzi@gmail.com

Nova Perspectiva Sistêmica, v. 29, n. 66, p. 22-35, abril 2020. 